\title{
Interactive comment on "The interaction between nitrogen and phosphorous is a strong predictor of intra-plant variation in nitrogen isotope composition in a desert species" by J. Zhang et al.
}

\section{Anonymous Referee \#2}

Received and published: 17 July 2016

This paper from Zhang et al. is intituled "The interaction between nitrogen and phosphorus is a strong predictor of intra-plant variation in nitrogen isotope composition in a desert species". In this paper, the authors aim to demonstrate the origin of the intraplant variations in dïĄd' $15 \mathrm{~N}$ by looking at its correlations with C,N,P concentration in different parts of the two desert plants in China. In general, this paper lacks details in background and analysis that makes it difficult to follow. In addition, the novelty of the paper stands at the comparison of dïA $d^{\prime} 15 \mathrm{~N}$ with other nutrients content and the analysis of a particular plant in China. The analysis of the data is not convincing and lack of deep analysis. Finally, the discussion is long and purely speculative when many of the speculation could have been supported by data eventually. Here are specific

Printer-friendly version

Discussion paper 
details that could help improve the manuscript:

Introduction: This part is too long but somehow informative. Shortening the introduction incorporating specific details on fractionation factors and natural variations of İĄ' $15 \mathrm{~N}$. The introduction is plagued by a lack of precision in the words used, especially with unnecessary adverbs and superlative. L.70: "plant photosynthesis, growth and metabolism and substrate supply for microbial activities" Why do you speak about microbial activity here, if you have no data to support it, why Photosynthesis if not measured? L.73: "rarer $\mathrm{N}$ isotope 15" ... "more abundant" why not using natural isotope composition. L. 81: "types of mycorrhizal fungi" Are you planning to measure it? If so where are the data? Do you have measured soil dïĄd'15N? L.87: "relatively few studies" what does it mean? L.86-89: these 2 sentences seem in opposition. L.100102: If both metabolisms are different could be useful to detail the discrimination factor and why is it so different. L.120: "This assumption led to the belief that organic $\mathrm{N}$ compounds...." It sounds like you are saying that science believes not that science is based on fact! Need to be rephrased. L.129: "which has a large isotope effect" how much?

Material and methods It is surprising that no analysis of the soil dïAd' $15 \mathrm{~N}$ was carried out. Statistical analyses: No detail on the analysis of slope of the regression was given. Arcsin analysis of slope sounds appropriate. Please explain how you obtain your $p$ values in the correlations.

Results L.316-319: Since no data on the difference of dïĄd'15N in soil at both sites was given, it is difficult to tell if this conclusion is not only associated with soil ïAd' $15 \mathrm{~N}$ variability. L.340:"Since fine roots differ from other organs in that fine roots are the primary organs for nitrate reduction" Your data are actually showing the opposite since the ïAd' $15 \mathrm{~N}$ is way above the dïAqd' $15 \mathrm{~N}$ of all organs. If fine roots were the main site of reduction of $\mathrm{N}$ then you should expect transport of amino acids to the leaves and a more homogeneous ïĄ'15N between roots and leaves. In addition, if this means for the authors that $\mathrm{NH} 4$ is transported to the leaves, then there is still a $16-20$ per mil

Printer-friendly version

Discussion paper
Interactive comment 
fractionation by the NR that should be taken into account and should show the higher difference in dïA d'15N. dïA d'15N data should be presented relative to the substrate (soil $\mathrm{NO} 3$ or $\mathrm{NH} 4$ ) or relative to the origin (root). Finally, a lot of the correlations were made using the data for all organs and leaves. In many cases, the 6 data points of the leaves affect the correlation. If leaves are removed from the data for this analysis, a different correlation could be found. Finally, since metabolisms of roots and leaves are likely to be different as suggested by the authors, at least in term of reduction of $\mathrm{N}$ sources, it could be interesting to present correlation by organs instead of pooling them. In figure 3 and 5, if leaves are removed from the graph, the correlation between $\mathrm{d} 15 \mathrm{~N}$ and $\mathrm{P}$ disappear highlighting the need to do the organ-specific analysis.

Discussion Overall the discussion is very well written and clear. It may lack a conceptual framework. Many of the explanation in the text stand on speculation more than the data presented. There is a clear disconnection between the interesting debate of the relationship between $d 15 \mathrm{~N}$ and $\mathrm{P}$ and the data presented. An example of this discrepancy is the many recalls to the reader of the focus on leaves (L.404, L.419). The utilization of unnecessary abbreviations clouds the main information. L. $361-363$, why do you use EFO, IFO, and EIFT when you will be using it only 2-3 times? Simply use words, it is not much longer. L.358-359: Is there a way to present this synthesis into a simple graph? L.363: "External factors include different sources of nitrogen" Since you recognized it is an important factor, why no data were shown?

Interactive comment on Biogeosciences Discuss., doi:10.5194/bg-2016-231, 2016. 